\title{
Translational regulation of ferritin synthesis in rat liver
}

\author{
Effects of chronic dietary iron overload
}

\author{
Gaetano CAIRO,, Lorenza TACCHINI,* Luisa SCHIAFFONATI,* Emilia RAPPOCCIOLO,* Ezio VENTURA $\dagger$ \\ and Antonello PIETRANGELO $\ddagger$ \\ * Istituto di Patologia Generale, Centro di Studio sulla Patologia Cellulare CNR, Via Mangiagalli 31, 20133 Milano, and \\ † Clinica Medica III, Università di Modena, Via Del Pozzo 71, 41100 Modena, Italy
}

\begin{abstract}
In rats with chronic dietary iron overload, a higher amount of liver ferritin L-subunit mRNA was found mainly engaged on polysomes, whereas in control rats ferritin L-subunit mRNA molecules were largely stored in ribonucleoprotein particles. On the other hand, ferritin H-subunit mRNA was unchanged by chronic iron load and remained in the inactive cytoplasmic pool. In agreement with previous reports, in rats acutely treated with parenteral iron, only the ferritin L-subunit mRNA increased in amount, whereas both ferritin subunit mRNAs shifted to polysomes. This may indicate that, whereas in acute iron overload the hepatocyte operates a translation shift of both ferritin mRNAs to confront rapidly the abrupt entry of iron into the cell, during chronic iron overload it responds to the slow iron influx by translating a greater amount of L-subunit mRNA to synthesize isoferritins more suitable for long-term iron storage.
\end{abstract}

\section{INTRODUCTION}

Ferritin is a ubiquitous protein committed to store iron in a soluble non-toxic form within a shell of 24 subunits comprised of $\mathrm{H}$ - and L-chains [1]. The synthesis of both ferritin chains is stimulated by iron [2-4], and recent confirmations of early evidence [5] emphasized the importance of translational regulation for this response. Indeed, the effect of iron is mediated by one or more repressors [6-8], which interact with a specific ironresponsive element in the $5^{\prime}$ untranslated region of ferritin mRNAs $[9,10]$. A diminution in this binding in the presence of elevated iron pools results in a rapid shift of ferritin mRNAs from the ribonucleoprotein particles fraction to the polysomes $[11,12]$. Nevertheless, regulation of ferritin synthesis occurs at multiple levels, since increased transcription of the ferritin L-subunit gene caused by iron has been demonstrated both in rat liver [13] and in cultured human cells [4], and posttranscriptional regulatory mechanisms have been found in human erythroleukaemic cells [14]. All these results, which have helped our understanding of the mechanisms of induction of ferritin synthesis in response to iron, have been obtained with cultured cells or intraperitoneal acute iron loading.

Though suitable for experimental studies and easy to manipulate, these models are not very representative of the events occurring in human chronic-iron-overload states in which iron accumulates slowly but progressively with time $[15,16]$. A suitable model for the study of iron metabolism under these conditions is the rat chronically fed a diet enriched in elemental iron [15-17]. In order to investigate the effect of chronic iron overload on the expression of ferritin $\mathrm{H}$ and $\mathrm{L}$ genes, we analysed ferritin accumulation, the steady-state levels of ferritin mRNAs and their distribution on polysomal and non-polysomal subcellular fractions in the liver of rats made siderotic by feeding an iron-enriched diet for several months. The data were compared with those obtained in rats exposed to acute intraperitoneal iron load.

\section{METHODS}

Animals

Female albino rats (100-120 g body wt.) were housed in stainless-steel cages and fed a diet supplemented with $3 \%(\mathrm{w} / \mathrm{v})$ carbonyl iron (Fluka Chemia AG, Buchs, Switzerland) for 30 weeks. Sex- and age-paired rats, fed a chow diet alone, were taken as controls or injected intraperitoneally with $400 \mu \mathrm{g}$ of iron/100 g body weight

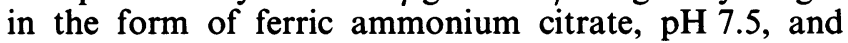
killed $4 \mathrm{~h}$ later. Iron-treated and control rats were killed by decapitation; the liver was removed, weighed and divided into portions, one of which was frozen in liquid $\mathrm{N}_{2}$ for a subsequent extraction of total RNA and ferritin determination. A second portion was used for iron evaluation and the remainder for polysome fractionation.

\section{Iron and ferritin determination}

Liver iron was evaluated by flameless atomic-absorption spectroscopy. Briefly, liver specimens were homogenized with $0.02 \mathrm{M}$-acetate buffer, $\mathrm{pH} 4.8$ (containing $\left.0.02 \% \mathrm{NaN}_{3}\right)$, at a ratio of $1: 20(\mathrm{w} / \mathrm{v})$. Samples $(20 \mu \mathrm{l})$ were added to $200 \mu \mathrm{l}$ of $0.05 \mathrm{M}-\mathrm{HNO}_{3}$ and analysed with an atomic-absorption spectrophotometer (model 5000; Perkin-Elmer Corp., Norwalk, CT, U.S.A.) [18]. Liver ferritin concentration was determined with a microtitre sandwich enzyme immunoassay as described in [19], using rabbit anti-(rat ferritin) IgG. The assay had a sensitivity range between 10 and $500 \mathrm{ng} / \mathrm{ml}$, with intraand inter-assay variabilities below $15 \%$.

$\ddagger$ Present address and address for correspondence and reprint requests: Liver Research Center, Albert Einstein College of Medicine, 1300 Morris Park Avenue, Bronx, NY 10461, U.S.A.

Vol. 264 


\section{Solution of total RNA}

Total liver RNA was purified by the method of Chomczynski \& Sacchi [20], quantified spectrophotometrically and subjected to Northern-blot analysis.

\section{Fractionation of cytoplasmic RNA}

The liver was homogenized in 2 vol. (w/v) of $0.25 \mathrm{M}$ sucrose in TKM [0.05 M-Tris/ $\mathrm{HCl}(\mathrm{pH} \mathrm{7.8)/0.025} \mathrm{M-}$ $\mathrm{KCl} / 5 \mathrm{mM}-\mathrm{MgSO}_{4} / \mathrm{RNasin}$ (ribonuclease inhibitor; 500 units $/ \mathrm{ml}$; Promega, Madison, WI, U.S.A.)] and centrifuged at $12000 \mathrm{~g}$ for $20 \mathrm{~min}$ to obtain a post-mitochondrial supernatant (PMS). After treatment with sodium deoxycholate (final concentration $1 \%$, w/v), post-mitochondrial supernatant was layered over a $13 \mathrm{ml}$ $15 / 50 \%-(\mathrm{w} / \mathrm{v})$-sucrose gradient in TKM and spun at $283000 \mathrm{~g}$ for $135 \mathrm{~min}$. The polysome profile of the gradient was monitored by u.v. absorption at $260 \mathrm{~nm}$, and five fractions were collected. The RNA was recovered from each fraction by ethanol precipitation. The RNA was resuspended in $0.1 \mathrm{M}-\mathrm{NaCl} / 2.5 \mathrm{~mm}$-EDTA $/ 1 \%$ $\mathrm{SDS} / 20 \mathrm{~mm}$-Tris/HCl, pH 7.4, extracted twice with phenol/chloroform $(1: 1, \mathrm{v} / \mathrm{v})$ and precipitated with ethanol. After centrifugation, RNA was resuspended in sterile water and subjected to Northern-blot analysis.

\section{Northern-blot analysis}

Aliquots of RNA (equal amounts of total RNA or equal volumes from gradients fractions) were electrophoresed under denaturing conditions, blotted to Hybond C Extra filters (Amersham) and hybridized with the various probes as previously described [4]. The probes were labelled with $\left.{ }^{32} \mathrm{P}\right] \mathrm{dCTP}$ by nick translation using a commercial Kit (Amersham International). For quantitative determinations, autoradiograms were scanned by laser densitometry, making sure that the exposure was in the linear range of the film. Equal amounts of RNA were loaded in each lane of the gels as determined by hybridization of rRNA with the pXCR7 probe on the same filter.

\section{Probes}

The cDNAs for the $\mathrm{H}$ - and L-subunit of rat ferritin, the cDNA for rat serum albumin and the pXCR7 clone containing a Xenopus rDNA unit were kindly provided by Dr. H. N. Munro (Department of Applied Biological Science, Massachussetts Institute of Technology, Cambridge, MA, U.S.A.), Dr. J. Bonner (Division of Biology, California Institute of Technology, Pasadena, CA, U.S.A.) and Dr. I. Bozzoni (Centro Acidi Nucleici, CNR, Roma, Italy) respectively.

\section{RESULTS}

The effect of chronic and acute administration of iron on liver iron and ferritin content is reported in Table 1. Liver iron was dramatically higher in chronically treated rats than in their control counterparts, whereas acute administration caused only a slight increase. Specific iron staining of liver sections (Perls' Prussian Blue) confirmed the results of atomic-emission spectroscopy (not shown). The different levels of liver iron content obtained in the two iron-treated groups were reflected in a strong difference in the amount of liver ferritin between chronically and acutely iron-poisoned rats (Table 1).

The Northern blots of total cellular RNA shown in
Table 1. Effect of iron overload on iron and ferritin content of rat liver

Liver iron and ferritin were determined by atomic-absorption analysis and by a microtitre sandwich enzyme immunoassay respectively as described in the Methods section. Results are expressed as means \pm S.D. for three separate experiments. Significantly different from control: ${ }^{*} P<0.05 ;{ }^{* *} P<0.005 ;{ }^{* * *} P<0.0001$.

\begin{tabular}{llll}
\hline & \multicolumn{3}{c}{ Content $(\mu \mathrm{g} / \mathrm{g}$ of tissue) } \\
\cline { 2 - 4 } \multicolumn{1}{c}{ Treatment ... } & Control & Chronic & Acute \\
\hline Liver iron & $130 \pm 16$ & $2110 \pm 345^{* * *}$ & $250 \pm 21^{*}$ \\
Liver ferritin & $237 \pm 12$ & $1359 \pm 141^{* *}$ & $280 \pm 24$ \\
\hline
\end{tabular}

Fig. 1 indicates that L-subunit mRNA was appreciably increased over the level of the control in chronically as well as in acutely treated rats $(2-2.5$-fold as determined by densitometric quantification; Fig. 1). By contrast, Hsubunit mRNA levels were not significantly affectea in either of the iron-treated groups (Fig. 1). Moreover, iron treatments did not cause appreciable changes in the relative amount of a liver-specific gene such as that of albumin (Fig. 1).

The Northern blots of RNA extracted from individual fractions collected across sucrose gradients of post-
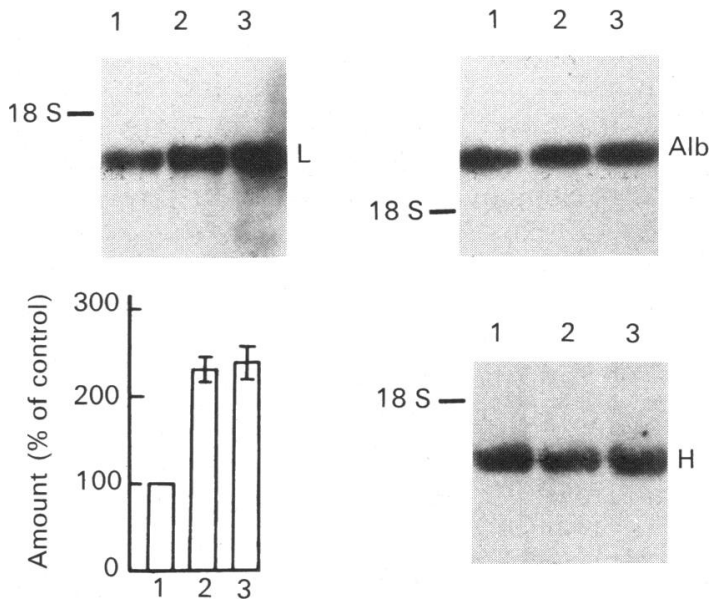

Fig. 1. Effect of iron overload on the steady-state levels of ferritin $\mathrm{L}$ - and $\mathrm{H}$-subunit mRNAs in rat liver

Total cellular RNA $(30 \mu \mathrm{g})$ isolated from the livers of control or iron-treated rats was electrophoresed for $4 \mathrm{~h}$ at $80 \mathrm{~V}$ in a $1.2 \%-(\mathrm{w} / \mathrm{v})$-agarose gel under denaturing conditions, blotted to nitrocellulose filters and hybridized to L-subunit (L), H-subunit (H) and albumin (Alb) probes. Three separate sets of experiments were performed. Autoradiograms from one representative experiment are shown. At the left of each blot the migration position of $18 \mathrm{~S}$ rRNA is indicated. Histograms represent the densitometric quantification of the relative amount of $\mathrm{L}$-subunit mRNA, determined as described in text by scanning different exposures of filters; values are means for three experiments with the range indicated by vertical bars. RNA loading was checked as described in the Methods section. Lane 1, control rat; lane 2, chronically iron-treated rat; lane 3, acutely iron-treated rat. 

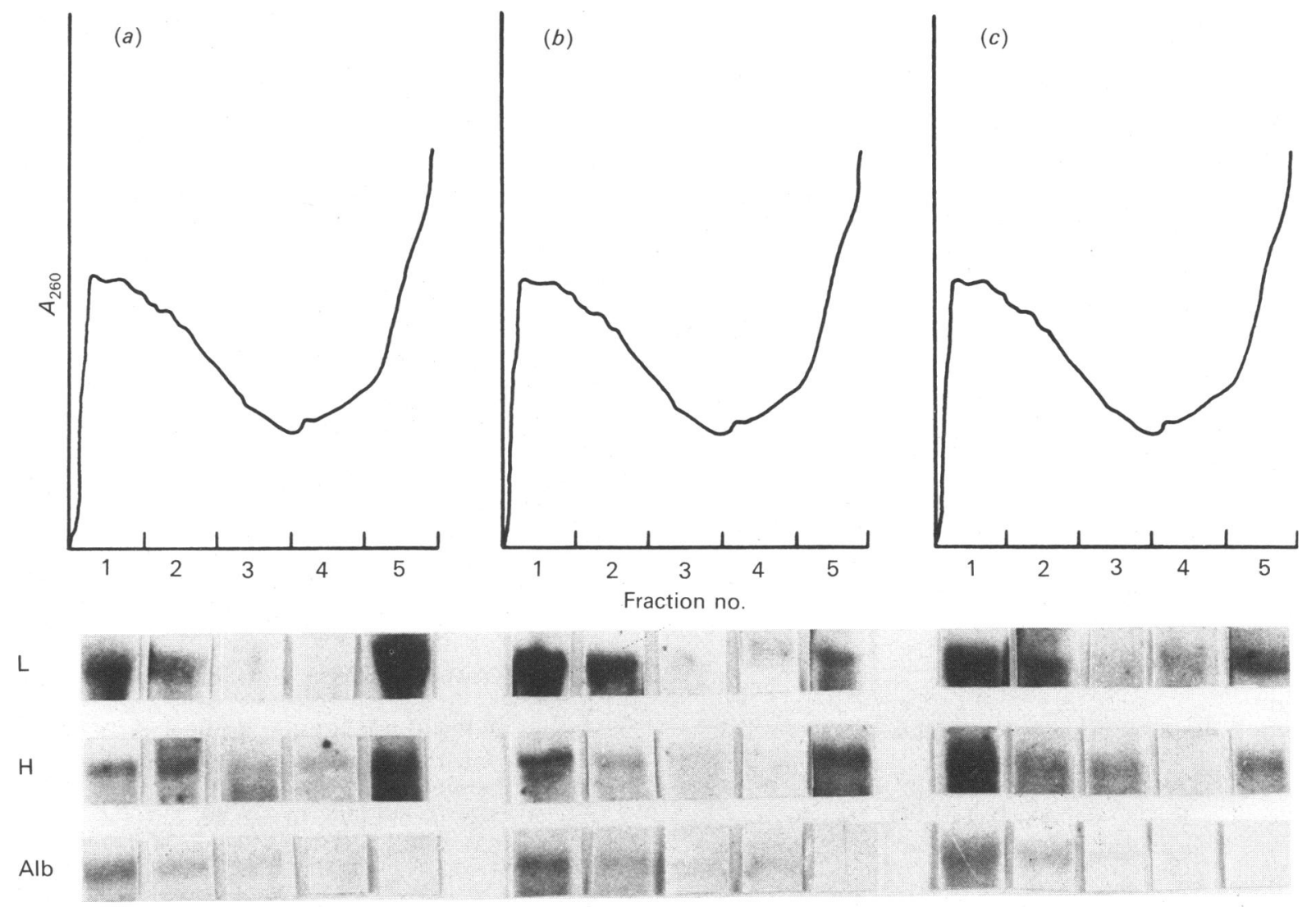

Fig. 2. Effect of iron overload on polysomal distribution of ferritin L- and H-subunit mRNAs

Post-mitochondrial supernatant was prepared and sedimented in a sucrose gradient as described in the Methods section and the polysome profiles of the gradient were monitored by u.v. absorption at $260 \mathrm{~nm}$. Direction of sedimentation was from right to left. RNA was extracted from individual fractions, analysed by Northern blot and hybridized to L-subunit (L), H-subunit (H) and albumin (Alb) probes. Three separate sets of experiments were performed, and autoradiograms from one representative experiment are shown. $(a)$ Control rat; $(b)$ chronically iron-treated rat; $(c)$ acutely iron-treated rat.

mitochondrial supernatant (Fig. 2) show that, as already reported [11], both ferritin mRNAs are shifted to the polysomes after acute iron administration. In chronically loaded rat livers, while the L-subunit mRNA is significantly shifted to the polysomes with the amount of mRNA remaining in the ribonucleoprotein fraction even lower than in intraperitoneally treated rats, the $\mathrm{H}$-subunit mRNA distribution is unchanged. Hybridization of the same blots with a probe for albumin showed no differences in the mRNA distribution between control and treated rats, thus indicating the specificity of these translational shifts for ferritin mRNAs.

\section{DISCUSSION}

We have investigated the molecular mechanism for increased ferritin synthesis in a model of iron overload (i.e. chronic dietary iron overload) where a slow but progressive liver iron load through the portal vein during a period of several months occurs. Thus, iron deposition and ferritin accumulation in the liver are dramatically higher than in acutely treated rats and reach levels more comparable with those found in humans with iron-overload states [21]. Moreover, whereas after parenteral iron load the metal is mainly found in non-parenchymal cells, in chronic enteral treatment with elemental iron there is a preferential deposition in the hepatocytes [17,21,22]. At the molecular level the effects of acute and chronic iron overload are quite similar as regards the ferritin Lsubunit. Indeed, we demonstrate also that, during chronic iron overload, ferritin L-subunit mRNA is significantly increased and largely engaged on polysomes, as had already been shown in the acute condition [13]. The much higher ferritin accumulation found in chronically iron-loaded rats is possibly due to the continuous ferritin gene activation. However, the polysomal shift of the $\mathrm{H}$ subunit mRNA described in acutely treated rats [11] is not present in the chronic situation. The latter finding may indicate that, under acute iron-overload conditions, along with the concomitant activation of L-ferritin gene transcription, the translational shift of both subunits represents the fastest response that liver cells may adopt to confront the abrupt entry of iron into the cell. In fact, this allows a rapid synthesis of a greater amount of isoferritins containing also the $\mathrm{H}$ subunit, which is useful in rapidly taking up and releasing excess iron [23,24]. On the other hand, during chronic dietary iron overload, the entry of the metal into the cell is slow, and thus the hepatocyte needs to synthesize large amounts only of isoferritins rich in L-subunit, which is more suitable for storing $[3,13,23,24]$ the toxic iron coming from the gut. To this purpose a greater amount of L-subunit mRNA is 
kept specifically engaged on polysomes and actively translated.

We thank Professor Aldo Bernelli-Zazzera for reading the manuscript and for useful discussion, and Dr. Anna Cozzi for performing the ferritin immunoassay. This work was supported by grants from the Consiglio Nazionale delle Ricerche (CT 88.01959.04) and from the Ministero Pubblica Istruzione of Italy.

\section{REFERENCES}

1. Theil, E. C. (1987) Annu. Rev. Biochem. 56, 289-315.

2. Kohgo, Y., Yokoto, M. \& Drysdale J. W. (1980) J. Biol. Chem. 255, 5195-5200

3. Bomford, A., Conlon-Hollingshead, C. \& Munro, H. N. (1981) J. Biol. Chem. 256, 948-955

4. Cairo, G., Bardella, L., Schiaffonati, L., Arosio, P., Levi, S. \& Bernelli-Zazzera, A. (1985) Biochem. Biophys. Res. Commun. 133, 314-321

5. Zahringer, J., Baliga, B. S. \& Munro, H. N. (1976) Proc. Natl. Acad. Sci. U.S.A. 73, 857-861

6. Leibold, E. A. \& Munro, H. N. (1988) Proc. Natl. Acad. Sci. U.S.A. 85, 2171-2175

7. Rouault, T. A., Hentze, M. W., Caughman, S. W., Harford, J. B. \& Klausner, R. D. (1988) Science 241, $1207-1210$

8. Walden, W. E., Daniels-McQueen, S., Brown, P. H., Gaffield, L., Russel, D. A., Bielser, D., Bailey, L. C. \& Thach, R. E. (1988) Proc. Natl. Acad. Sci. U.S.A. 85, 9503-9507

9. Aziz, N. \& Munro, H. N. (1987) Proc. Natl. Acad. Sci. U.S.A. 84, 8478-8482

Received 28 June 1989/26 September 1989; accepted 24 October 1989
10. Hentze, M. W., Caughman, S. W., Casey, J. L., Koeller, D. M., Rouault, T. A., Harford, J. B. \& Klausner, R. D. (1988) Gene 72, 201-208

11. Aziz, N. \& Munro, H. N. (1986) Nucleic Acids Res. 14, 915-927

12. Campbell, C. H., Solgonick, R. M. \& Linder, M. C. (1989) Biochem. Biophys. Res. Commun. 160, 453-459

13. White, K. \& Munro, H. N. (1988) J. Biol. Chem. 263, 8938-8942

14. Mattia, E., Den Blaauwen, J., Ashwell, G. \& Van Renswoude, J. (1989) Proc. Natl. Acad. Sci. U.S.A. 86, 1810-1805

15. McLaren, G. D., Muir, W. A. \& Kellermeyer, R. W. (1983) Crit. Rev. Clin. Lab. Sci. 19, 205-266

16. Bassett, M. L., Halliday, J. W. \& Powell, L. W. (1984) Semin. Liver Dis. 4, 217-227

17. Bacon, B. R., Tavill, A. S., Britthenam, G. M., Park, C. H. \& Recknagel, R. O. (1983) J. Clin. Invest. 71, 429-439

18. Rocchi, E., Gibertini, P., Cassanelli, M., Pietrangelo, A. \& Ventura, E. (1986) J. Lab. Clin. Med. 107, 36-42

19. Schiaffonati, L., Rappocciolo, E., Tacchini, L., Bardella, L., Arosio, P., Cozzi, A., Cantu, B. G. \& Cairo, G. (1988) Exp. Mol. Pathol. 48, 174-181

20. Chomozynski, P. \& Sacchi, N. (1987) Anal. Biochem. 162 156-159

21. Bacon, B. R., Healey, J. F., Brittenham, G. M., Park, C. H., Nunnari, J., Tavill, A. S. \& Bonkowsky, H. (1986) Gastroenterology 90, 1844-1853

22. Pechet, G. S. (1969) Lab. Invest. 20, 119-126

23. Wagstaff, M., Worwood, M. \& Jacobs, A. (1978) Biochem. J. 173, 969-977

24. Mann, S., Baumster, J. V. \& Williams, R. J. (1986) J. Mol. Biol. 188, 225-232 